\title{
PELATIHAN BAHASA RUSIA UNTUK MENINGKATKAN KINERJA TNI AD DALAM BIDANG HELIKOPTER SERI MI
}

\author{
Susi Machdalena1, Anggraeni Purnama Dewi ${ }^{2}$, Nany Ismail ${ }^{3}$ \\ 1Jurusan Sastra Rusia, Universitas Padjadjaran \\ ${ }^{2}$ Jurusan Sastra Rusia, Universitas Padjadjaran \\ 3Jurusan Perancis, Universitas Padjadjaran \\ Email: ${ }^{1}$ machdalena@unpad.ac.id, 2anggraeni.purnama@gmail.com, \\ 3nany.ismail@unpad.ac.id
}

\begin{abstract}
In the present year, the helicopter MI belongs to 'Indonesian National Armed Force' (TNI-AD) is an advanced helicopter produced by Russia. In Indonesia, it is operated not only for guarding the Indonesian's areas, but also as a shuttle for sending and fetching people from/to the remote areas in the country. Other usage of the helicopter are as the transportation to send the logistic to the remote areas, to evacuate injured people by working-accident or by having an accident in difficult areas. The helicopter is also able to carry, at least, 12 passengers in lying position. This helicopter has many benefits to implement the duty around the remote places of Indonesia, especially the places that are difficult to reach by the ordinary transportation. Since all the guide books are written in Russian language, the officers who are going to operate the helicopter should learn Russian language. While the base Camp of the helicopters are in two places, Jakarta (the capital city) and Semarang (in West Java). Therefore, the language training is conducted in Cimahi, West Java. The participants who learn the Russian language are 12 officers, 2 officers are pilots, another 2 officers are co-pilots, 6 officers mechanics, and 2 other officers are the mechanics for spare-part services. This method uses descriptive method with grammar translation method, oral approach, and lexical approach. The results from the language training are about 8 officers are able to communicate, to write and to read fluency in Russian language, other 2 officers are able but not fluency in talking, writing and reading Russian. Unfortunately, other 2 officers still have difficulties in learning the Russian language.
\end{abstract}

Key Words: training, Russian language, performance, TNI-AD

\begin{abstract}
Abstrak
TNI AD memiliki helikopter seri MI yang diproduksi di Rusia. Helikopter ini digunakan untuk kepentingan pengiriman logistik, pengantaran dan penjemputan anggota TNI AD yang bertugas di Indonesia bagian Timur, transportasi bagi orang-orang yang mengalami kecelakaan baik kecelakaan kerja maupun yang terkena musibah. Helikopter ini merupakan helikopter tercanggih di kelasnya karena bisa mengangkut pasien-pasien dalam posisi berbaring sebanyak 12 orang. Helikopter ini sangat membantu TNI AD dalam melaksanakan tugas-tugas yang berada di daerah-daerah terpencil khususnya daerah-daerah yang sulit dijangkau alat transportasi lain, seperti Papua. Semua keterangan yang terdapat baik di dalam helikopter maupun buku-buku manual ditulis dalam Bahasa Rusia. Oleh karena itu anggota TNI AD yang bekerja di bidang helikopter ini wajib mempelajari bahasa Rusia. Base camp helikopter ini terdapat di Semarang dan di Jakarta. Dengan demikian kesatuan yang menangani helikopter ini selalu mengirim para anggotanya untuk mempelajari bahasa Rusia. Pelatihan diadakan di pusat pendidikan yang bertempat di Cimahi. Peserta pelatihan sebanyak 12 orang yang terdiri dari 2 orang pilot 2 orang co-pilot, 6 orang teknisi, dan 2 orang dari bagian pemeriksa suku cadang. Metode yang digunakan adalah metode deskriptif dengan pendekatan Grammar translation method, oral approach, lexical approach. Hasil yang diperoleh dari kegiatan ini adalah sebanyak 8 orang mampu berkomunikasi, menulis, serta membaca dan paham bahasa Rusia, 2 orang hanya mampu berkomunikasi secara terbatabata dan membaca memahami teks memerlukan waktu yang lebih lama, dan 2 orang lainnya tidak berhasil sama sekali.
\end{abstract}


Kata Kunci: pelatihan, bahasa Rusia, kinerja, TNI AD

\section{PENDAHULUAN}

Hubungan Rusia-Indonesia pada sepuluh tahun terakhir ini semakin baik Hal ini terlihat dari salah satunya realisasi hubungan diplomatik kedua negara yang ditandai dengan penendatanganan nota kesepakatan (MoU). Banyak MoU yang ditandatangni oleh kedua negara dalam berbagai bidang (Wawancara daring dengan Duta Besar Indonesia untuk Frderasi Rusia tanggal 17 September 2021).

TNI AD memerlukan jenis helikopter untuk keperluan logistik, pengantaran dan penjemputan para anggota TNI AD yang di tugaskan di Indonesia bagian Timur. Indonesia Timur khususnya Papua merupakan daerah yang indah dan letaknya dikeliling pengunungan sehingga transportasi yang memungkinkan digunakan adalah helikopter. Semua barang yang digunakan untuk kehidupan diangkut dengan menggunakan helikopter. Helikopter yang digunakan oleh TNI AD adalah helikopetar seri MI (Wawancara dengan pilot helokopter seri Mi periode Februari - Mei 2021 di Cimahi). Keunggulan helokopter ini dapat mengangkut 30 orang anggota TNI bersenjata lengkap, 12 orang korban dalam posisi berbaring beserta alat-alat medisnya. Helikopter ini dilengkapi juga dengan alat-alat senapan mesin yang dipasang di bagian depan. Memiliki dua mesin utamanya berupa mesin turbin gas dengan kapasitas 1,900 HP (bila terjadi mesin pertama tidak berfungsi maka mesin kedua dapat digunakan, dengan kapasitas 2,200 HP). Terdapat dua tangki bahan bakar tambahan dapat dipasang di kabin kargo, yang secara signifikan meningkatkan jangkauan jelajah helikopter. Helikopter ini juga dilengkapi dengan peralatan avionik baru yang memungkinkan untuk terbang pada siang dan malam hari. Selain itu, helikopter ini dilengkapi juga dengan alat-alat perang elektronik yang canggih.

(авиару.pф/aviamuseum/aviatsiya/sssr/verto lety/vertolety-kb-milya/mnogotselevojvertolet-mi-17-2/mnogotselevoj-vertolet-mi-17-
$1 \mathrm{v} /$ ). Menurut pilot helicopter ini dalam hal alih teknologi pihak Rusia lebih koopertaif dan lebih mudah mengadakan kontak-kontak dengan ahliahli helicopter ini baik melalui email maupun melalui tatap muka langsung. Pihak Rusia memberikan kesempatan yang luas untuk melakukan alih teknologi di Rusia bagi para pilotnya. Selain itu, dari segi harga pun kabarnya helicopter ini lebih murah bila dibandingkan dengan helicopter sejenis buatan Amerika. Dengan pertimbangan-pertimbanagn tersebut maka Depertemen Pertahanan memutuskan membeli helikopter seri MI sebanyak 12 buah dalam dua tahap. Kendala yang dialami hanya dalam bidang Bahasa. Oleh karena itu, Depertemen Pertahanan memutuskan untuk membuka pelatihan Bahasa Rusia bagi para pilot, co-pilot dan para teknisi helicopter ini untuk belajar Bahasa Rusia, karena semua keterangan untuk helikopter ini ditulis dalam bahasa Rusia. Oleh karena itu para anggota TNI AD yang berugas di bagian halikopter ini harus belajar bahasa Rusia. Bahasa Rusia diperlukan untuk alih teknologi, pelatihan-pelatihan para crew helikopter yang dilakulan di pusat pembuatan helikopter ini di kota Kazan Rusia (tujuan jangka panjang), memahami buku-buku panduan, mempu mengoperasikan helikopter ini, paham penggunaan tombol-tombol helikopter, perawatan helikopter, mampu berkomunikasi dengan para ahli dan teknisi dari Rusia yang datang ke Semarang dan Jakarta di mana helokopter MI ini di tempatkan.

Setelah 30 tahun belajar Bahasa Rusia saya merasakan bahsa bahasa Rusia merupakan salah satu bahasa yang tergolong sulit . Kesulitan bahasa Rusia terletak di antaranya pada kaidah-kaidah gramatika yang sangat kompleks dan leksika yang kaya. Dalam bahasa Rusia terdapat sbb.

- Sepuluh kelas kata yang terdiri dari enam kelas kata yang dapat berdiri sendiri (имя сущесвтительное /imja suščestvitel'noe/ 'nomina', /имя прилагательное /imja prilagatel'noe/ 'adjektiva', числительное 
/Čislitel'noe/ 'numeralia', местоимение /mestoimenie/ 'pronomina', глагол /glagol/ 'verba') dan empat kata yang tidak dapat berdiri sendiri (perlu bantuan kata lain agar dapat dimengerti artinya) adalah наречuе /narečie/ 'adverbia', предлог /predlog/ 'preposisi', союз / sojuz/ 'konjungsi', частица /častitsa/ 'partikel', междометие /meždometie/ 'interjeksi' (Живкович И. Zhikovich. I, 2021).

- Nomina, adjektiva, pronomina bahasa Rusia berubah berdasarkan gender pod /rod/ 'gender', jumlah число /čislo/ 'bilangan', dan kasus падеж / padež/ 'kasus'. Gender nomina dan adjektiva terdiri atas tiga yaitu maskulin мужской род /mužkoj rod/ 'gender maskulin', feminine женский род /ženskyj rod/ 'gender feminine', dan netral средний pod / srednyj rod/ 'gender netral', sedangkan untuk pronomina hanya terdapat dua gender, yaitu мужской род /mužkoj rod/ 'gender maskulin', feminine женский род /ženskyj rod/ 'gender feminine' (Kurmaeva N. M., 2021).

- Nomina berubah pula berdasarkan jumlahnya yaitu nomina tunggal единственое число /edinstvenoe čislo/dan nomina jamak множественое число /množestvenoe čislo/.

- Terdapat enam jenis kasus dalam bahasa Rusia yaitu kasus nominative (иминетельный /iminitel'nyj/), kasus genetif (родительный /roditel'nyj), kasus datif (дательный /datel'nyj/), kasus akusatif (винительный vinitel'nyj/), kasus instrumental (mворительный /tvoritel'nyj/, dan kasus preposisional (предложный падеж /predložnyjpadež/) (Chudinova, 2021)

Verba bahasa Rusia memiliki kategori gramatikal yang kompleks. Kategorikategori ini adalah konjugasi (спражение /spaženie/, kala (время /vrevja/, aspek (вид /vid/), управление /upravlenie/. Konjugasi verba adalah proses dan hasil perubahan verba berdasarkan persona dan jumlah Verba yang ditempatkan dalam kalimat berubah berdasarkan subjek kalimatnya. Terdapat tiga persona tunggal dan tiga persona jamak. Persona ini adalah $я$ /ja/ 'saya', mы /ty/ 'kamu', он /on/ 'dia laki-laki', она /ona/ 'dia perempиап', оно /оnо/ ' dia netral' мы /my/ 'kami', вы /oy/ 'Anda, kalian', они /oni/ 'mereka (Konstantinova, 2016). Berikut diberikan tabel perubahan nomina

Tabel 1. perubahan nomina tunggal

\begin{tabular}{|l|l|l|l|}
\hline \multirow{2}{*}{ Nama kasus } & \multicolumn{3}{|c|}{ Tunggal } \\
\cline { 2 - 4 } & $\begin{array}{c}\text { Maskuli } \\
\text { n }\end{array}$ & $\begin{array}{c}\text { Femini } \\
\text { n }\end{array}$ & Netral \\
\hline Nominatif & stol & kniga & okno \\
\hline Genenetif & stola & knigi & okna \\
\hline Datatif & stolu & knige & oknu \\
\hline Akusatif & stol & knigu & okno \\
\hline Instrumental & stolom & knigoi & oknom \\
\hline $\begin{array}{l}\text { Preposisiona } \\
1\end{array}$ & o stole & o knige & o okne \\
\hline \multicolumn{4}{|c|}{ Sumber: (Glazunova, 2017) } \\
\hline
\end{tabular}

Tabel 1 menjelaskan tentang perubahan nomina Stol 'meja', kniga 'buku tulis', dan okno 'jendela' yang berbeda gendernya dalam bentuk tunggal. Perubahan itu menunjukkan perubahan ketiga nomina tersebut dalam setiap kasus.

Tabel 2. Perubahan nomina jamak

\begin{tabular}{|l|l|l|l|}
\hline Nama kasus & \multicolumn{3}{|c|}{ Jamak } \\
\hline Nominatif & stoly & knigi & okna \\
\hline Genenetif & stolov & knig & okon \\
\hline Datatif & stolam & knigam & oknam \\
\hline Akusatif & stoly & knigi & okna \\
\hline Instrumental & stolami & knigami & oknami \\
\hline Preposisional & o stolax & o knigax & o oknax \\
\hline \multicolumn{4}{|c}{ Sumber: (Glazunova 2017) } \\
\hline
\end{tabular}

Sama halnya dengan table 1, table 2 ketiga nominanya berbentuk jamak.

Contoh buku manual

1.5 ОСНОВНЫЕ ВАРИАНТЫ ЗАГРУЗКИ И ЗАПРАВКИ ВЕРТОЛЕТА. ОПРЕДЕЛЕНИЕ ЦЕНТРОВКИ ВЕРТОЛЕТА СПОМОЩЬЮ РАСЧЕТА

(1) Для обеспечения в полете центровки вертолета в допустимых пределах загрузку вертолета производите в строгом 
соответствиис указаниями раздела 5.

(2) При перевозке в грузовой кабине вертолета крупногабаритных грузов, центр тяжести которых невозможно разместить между стрелками, а также при изменении состава съемного оборудования данного варианта применения вертолета произведите расчет массы и центровки вертолета.

Расчет производите в соответствии с указаниями Инструкции по загрузке и центровке вертолета Ми-17-1В.

Взлетная масса и нагрузка вертолета по вариантам загрузки приведены в таблице 1.1. Масса и центр тяжести пустого вертолета Ми-17-1В берется из формуляра. Все расчеты производите в соответствии с Инструкцией по загрузке и центровке вертолета Ми-17-1В.

(3) В любом из вариантов вертолет может выполнять спасательныеоперации, при этом на нем устанавливается бортовая стрела с лебедкой.

Pelatihan ini bertujuan untuk meningkatkan kinerja para anggota TNI AD dalam menangani kelikopter seri MI. Mereka diharapkan bisa berkomunikasi dengan penutur asli pada saat penutur asli ini datang ke tempat kerja mereka. Selain itu, mereka diharapkan bisa memahami buku manual helikopter MI. Walupun terdapat buku manual yang berbahasa Inggris akan tetapi orang Rusia akan menuntut mereka menggunakan manual berbahasa Rusia. Untuk dapat mengerti buku panduan berbahasa Rusia mereka pertama-tama membacanya dalam bahasa Inggris kemudian setelah pelatihan mereka dituntut untuk dapat membaca dalam bahasa Rusia. Hal ini akan dipraktekan pada saat penutur asli datang ke tempat mereka atau mereka kontak melalui email.

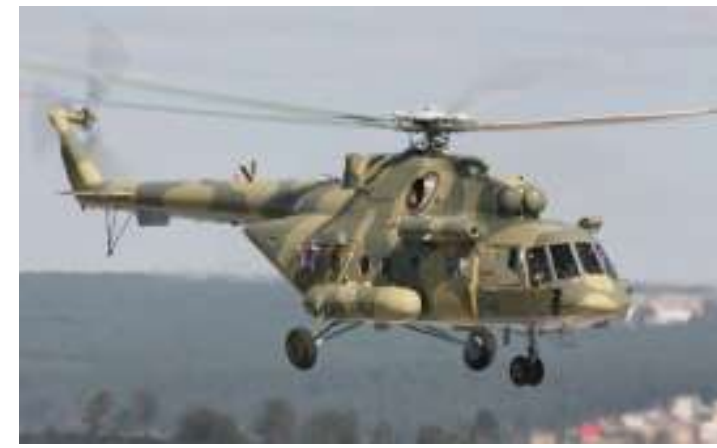

Gambar 1. Helikopter seri MI
Sumber gambar: https://avia.pro/blog/mi$\underline{17}$

\section{METODE PELAKSANAAN}

Metode yang digunakan dalam kegiatan ini adalah metode dekriptif dengan pendekatan Grammar translation Method, Audiolingual Method, Oral Approach, Lexical Approach (Funk, 2012; Sundari, 2017).

Kegiatan dibagi menjadi 3 bagian, di bulan pertama mendengarkan audio visual, membaca kosa kata, menulis kata-kata yang sudah didengar dan dibaca, gramatika dasar, membaca teks-teks pendek, membuat kalimat-kalimat pendek.

Bulan kedua mulai diberikan gramatika penggunaan kasus-kasus bentuk tunggal, kalimat-kalimat pendek untuk perkenalan, keluarga, pekerjaan, berbelanja, di rumah sakit, di bank, di bandara, di imigrasi. Menghafal dialog-dialog yang diberikan, menulis karangan pendek. Dialog yang dihafal dipresentasikan secara bergiliran lalu diberikan pertanyanpertanyaan tentang dialog yang ditugaskan kemudian peserta diminta untuk membuat pertanyaan dari dialog yang sudah dihafalkan. Menonton film pendek.

Bulan ketiga gramatika kasus-kasus dalam bentuk jamak, menulis karangan yang agak panjang dengan tema yang mulai beragam, percakapan mulai lebih panjang dan diberikan dialog-dialog secara spontan dalam berbagai tema. Menonton film setelah itu membuat resume dari film tersebut. Lomba pidato bahasa Rusia, tes akhir kegiatan.

\section{HASIL DAN PEMBAHASAN}

Kegiatan ini dimulai dengan Audiolingual Method untuk mendengarkan abjad Rusia. 


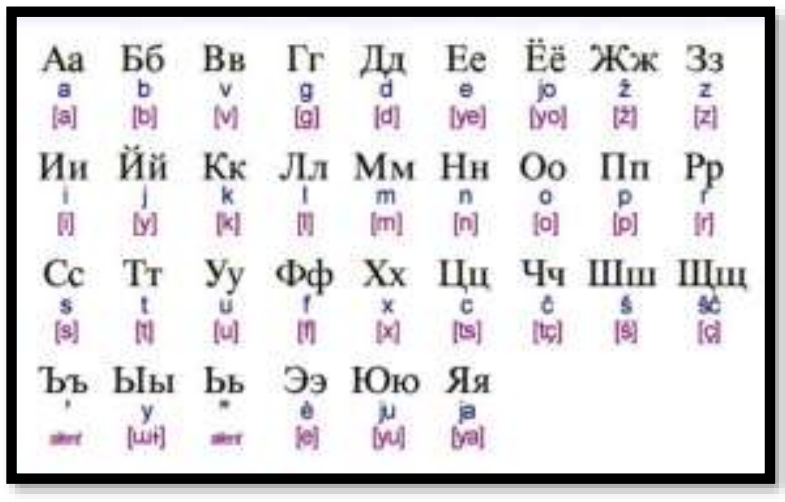

Tabel 3. Afabet Rusia. Sumber:

https://yandex.ru/images/search?pos=25\&img_url =https $\% 3 \mathrm{~A} \% 2 \mathrm{~F} \% 2 \mathrm{Fpbs}$.twimg.com $\% 2$ Fmedia $\% 2 \mathrm{FC1}$ q-

N9_WQAEtgiO.jpg\&text=russian\%20alphabet\&rpt=s image\&lr $=111965 \&$ source $=$ wiz\&stype $=$ image

- Video diputar berulang-ulang untuk mengucapkan huruf-huruf

- Dilatih mengucapkan abjad secara acak. pengajar menunjuk huruf-huruf secara acak dan peserta mengucapkannya.

- Diberikan frasa-frasa yang paling umum digunakan, misalnya terima ksih спасибо/spasibo/, selamat pagi доврое утро /dobroe utro/, selamat siang добыū день/dobryj den'/, selamat malam добый вечер/dobryj večer/ dan frasa yang digunakan pada saat berpisah досвидагия/dosvidanija/ (Живкович И. Zhikovich. I, 2021)

- Dilanjutkan dengan latihan menulis.

- Pekerjaan rumah mereka diperiksa dan diberi masukan pekerjaan mereka diberi nilai.

- Pada setiap pertemuan diberikan kosa kata sebanyak 100 kosa kata kata anggota keluarga (бpam / brat/ 'saudara laki-laki', bryк /vnuk/ 'cucu laki-laki'

- Nama-nama pakaian (contoh: блузка /bluzka/ 'blus', куртка /kurtka/ 'baju hangat', пиджак / pidžak/ 'blezer'.

- Nama-nama buah-buahan яблоко /jabloko/ 'apel', апельсин /apel'sin/ 'jeruk'.

- Bacaan (книга /kniga/'buku', словарь /slovar'/ 'kamus', газema /gazeta/ 'koran' журнал /žurnal/'majalah'.

- Alat-tulis (contoh: карандащ /karandaš. 'pinsil', бумага /bumaga/ 'kertas', ручка/ručka/'pulpen'.
- Bagian-bagian rumah beserta ruanganruangannya (комната / komnata/ 'kamar', стена /stena/ 'dinding', кухня / kuxnja/ 'dapur', ванная / vannaja/ 'kamar mandi'.

- Kosa kata yang ada di dapur (nacyda /pasuda/ 'pecah belah', холодилник /xolodilnik/ 'kulkas', печка /pečka/ 'kompor'.

- Kosa kata yang ada di kamar mandi (щётка /ščeka/ 'sisir', мыло /mylo/ 'sabun', зубная nacma / zubnaja pasta/'sikat gigi'.

- Kosa kata tentang kota (здание /zdanie/ 'gedung', улица /ulitsa/ 'jalan', город /gorod/ 'kota'; transport (автобус /avtobus/ 'bis', машина /mašina/ 'mobil', mрамвай /tramvai/ 'trem'; olah raga (мяч /mjač/ 'bola', спортсмен /sportsmen/ 'olahragawan', плавание / plavanie/ 'renang'; budaya (художник 'xudožnik/ 'seniman', музыка / muzyka/ 'musik'.

- Kosa kata tentang binatang ( $\kappa o m / k o t /$ 'kucing', ^омадь /lošad'/ 'kuda', собака /sobaka/ 'anjing';

- Kosa kata nama-nama bulan dan hari (январь /janvar'/ 'Januari' , феebpasь /fevral'/ 'Februari' dll. (Rogacheva E.N and Cemenova L.I., 2021).

Pronominal ( $я$ /ja/ 'saya', mb /ty/ 'kamu', он /on/ 'dia laki-laki', она /ona/ 'dia perempuan' (Живкович И. Zhikovich. I, 2021).

Semua kosa kata dibaca bekali-kali lalu dihafalkan kemudian ditest secara begiliran. Selain itu, diberikan juga dialog-dialog sederhana untuk dihafalkan peserta setiap hari.

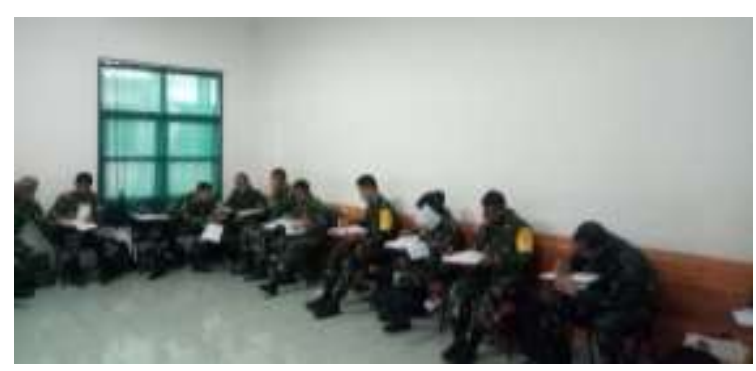

Gambar 2. Peserta pelatihan bahasa Rusia

Sumber: Foto pribadi (diambil pada tanggal 10 Maret 2021 di PUSDIK PENGMILUM Cimahi)

Di bulan kedua menggunakan Grammar translation Method untuk menjelaskan semua 
kaidah gramatika bahasa Rusia secara bertahap dimulai dari gender nomina, bentuk jamak, selanjutnya adjektiva beserta gendernya. Diberikan juga persesuaian adjektiva dengan nomina (краный пиджак/krasnyj pidžak/ 'jas merah', красная машина/krasnaja mašina/ 'mobil merah', красное окно/krasnoe okno/ 'jendela merah'. Setiap adjektiva harus sesuai dengan gender nomina . Kemudian digunakan juga, Lexical Approach dan Audiolingual Method. Berbekal leksika yang banyak maka peserta tidak sulit menyesuaikan adjektiva dengan nomina. Beriringan dengan latihan adjektiva dan nomina ini diberikan juga audio untuk mendengarkan teks. Giliran membaca setiap peserta untuk memperlancar penggunaan adjektiva dan nomina. Kemudian diputarkan film pendek dua kali secara penuh. Di akhir latihan ini peserta diminta menuliskan kata-kata yang mereka dengar dari film pendek tadi. Kami koreksi pekerjaan mereka dan dibahas kata-kata yang tidak jelas atau salah mereka tulis.

Bacaan dan dialog-dialog untuk percakapan terus ditingkatkan pada bacaan dan dialog yang mulai mengandung verba dan kasus-kasus. Kemudian diterangkan konjugasi verba (perubahan verba berdasarkan persona). Latihan konjugasi dilakukan secara terulis dan lisan. Setiap peserta mendapat giliran.

Setelah belajar verba maka dilanjutkan dengan menerangkan prinsip-prinsip kasus dalam bahasa Rusia. Setiap verba dalam bahasa Rusia menguasai kasus-kasus tertentu misalnya verba infinitive membaca uumamb /čitat'/ menguasai kasus akusatif (я читаю книгу, ты читаещь журнал /ja čitayu knigu, ty čitaeš' žurnal/ 'saya membaca buku, kamu membaca majalah'.

Untuk pengajaran kesus yang pertama diajarkan adalah perubahan nomina untuk kasus preposisional dan kasus akusatif untuk benda mati tunggal. Kemudian dilanjutkan dengan kasus datif, genetif dan kasus instrumental semua dalam bentuk tunggal. Sambil berjalan diberikan juga persesuain pronominal, adjektiva, dengan nomina dalam setiap kasusnya (Этот белый дом находится на улице Pahlawan / eto belyj dom naxoditsja na ulitse Pahlawan/ 'Rumah putih itu terletak di jalan
Pahlawan'). Kalmiat tersebut bersubjek nomina maskulin tunggal subjek этот белый дом / eto belyj dom/ 'rumah putih', pronominal demonstrative этот /etot/ 'itu', белый / belyj/ 'putih' bergender maskulin karena bersesuaian dengan nomina persona ketiga maskulin tunggal дом /dom/ 'rumah', begitu pula predikat kalimat tersebut находится /naxoditsja/ 'berada, terletak' merupakan konjugasi verba untuk persona ketiga tunggal. Dalam contoh kalimat itu predikat mengacu pada subjek persona ketiga tunggal. Begitu pula bila subjek bergender feminine atau bergender netral dan bentuk jamak (Kryuchkova Lyudmila Сергеевна Крючкова Людмила, 2021).

Teks-teks dan dialog-dialog untuk percakapan sudah semakin berkembang dengan tema-tema yang beragam. Membaca menghafal dialog dan tanya jawab serta menulis karangan terus dilatih sambil memperbaiki kesalahankesalahan gramatika, pilihan kata, dan susunan kalimat-kalimat yang mereka buat baik dalam lisan maupun dalam Bahasa tulisan.

Di bulan ketiga semua pendekatan digunakan secara bergantian. Grammar translation Method digunakan kembali untuk menjelaskan kaidah-kaidah gramatika tentang semua kasus nomina dan frasa nomina bentuk jamak (Funk, 2012). Hal ini tidak begitu sulit lagi dimengerti oleh peserta karena mereka sudah sebagian besar sudah memahami kasus-kasus dari nomina atau frasa nomina bentuk tunggal. Latihan-latihan untuk gramatika ini juga dilakukan hanya lebih berkonsentrasi pada perubahan nomina (frasa nomina) untuk semuakasus dalam bentuk jamak walupun bentuk tunggal tetap diberikan juga latihanlatihan.

Lexical Approach dan Audiolingual Method sera personal approach tetap digunakan (Funk, 2012). Pengayaan leksika peserta dilakukan memalui bacaan-bacaan, film, percakapan serta latihan-latihan gramatika. Teks yang diberikan sudah lebih panjang dan kaya akan kata-kata turunan, tema-tema dialog beragam di anatarnya dialog-dialog di pesawat terbang, pada saat check in di imigrasi, di bank, di restoran dll. Selan itu, diberikan juga hal-hal mengenai etiket yang berlaku dalam masysrakat 
Rusia, budaya Rusia juga menjadi salah satu materi pelatihan ini.

Di akhir kegiatan diadakan ujian akhir, lomba pidato, dan praktek menjadi guide. Ujian akhir diselenggarakan selama dua hari dengan pengawas dari pihak Pusat Pendidikan dan Pelatihan Cimahi. Materi untuk lomba pidato dipilih sendiri oleh masing-masing peserta dan setiap orang mempresentasikan hasil tulisannya di hadapan peserta semua pengajar dan beberapa orang staf dari Pusat Pendidikan dan Pelatihan Cimahi. Para pengajar memberikan nilai kemudian nilai tersebut disatuakan agar bisa dilihat peserta mana yang mendapat nilai paling baik maka akan menjadi juara pidato. Rangkain kegiatan diakhiri dengan prektek guide. Peserta akan menjadi guide untuk tempat-tempat bersejarah yang berada kota Cimahi. Peserta dan pengajar berkedaraan mobil "Bandros".

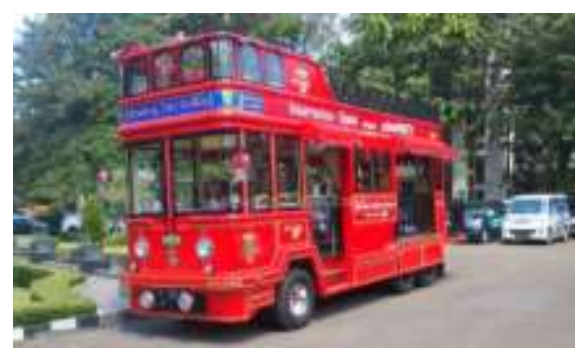

Gambar 3. Mobil Bandros

Sumber foto: Foto pribadi (diambil pada tanggal 22 April 2021 di Cimahi)

Penitia di Pusat Pendidikan dan Pelatihan memilihkan tempat-tempat yang memiliki sejarah. Tempat-tempat itu di anatarnya adalah Rumah Sakit Dustira, Alun-Alun Cimahi, Mesjid ABRI, Kampung Reundeu, Kuburan Belanda dll. Setiap peserta harus menerangkan tempat yang menjadi tugasnya. Kami berkeliling kota Cimahi di setiap tempat yang menjadi titik untuk peserta menerangkan tempat itu maka mobil akan berhenti dan peserta mulai menerangkan tempat tersebut waktu yang diberikan 10 menit untuk setiap peserta dan kami pengajar serta beberapa staf dari Pusat Pendidikan ikut serta. Pengajar dan staf dari Pusat pendidikan boleh bertanya kepada peserta, bila staf dari Pusat Pendidikan yang bertanya dalam bahasa Indonesia maka temannya yang mendapat giliran selanjutnya menerjemahkan ke dalam bahasa Rusia lalu peserta yang sedang menjadi guide menjawab dalam Bahasa Rusia kemudian diterjemahkan. Begitu seterusnya sampai semua peserta mendapat giliran. Praktek ini sangat menyenangkan semua peserta. Dalam prektek ini telihat peserta mana yang sudah menguasai bahasa Rusia dengan baik peserta mana yang masih belum menguasai.

Dalam acara penutupan pelatihan dan telah terpilih satu orang yang menjadi peserta terbaik maka juara ini harus pidato dihadapan komandan beserta para stafnya.

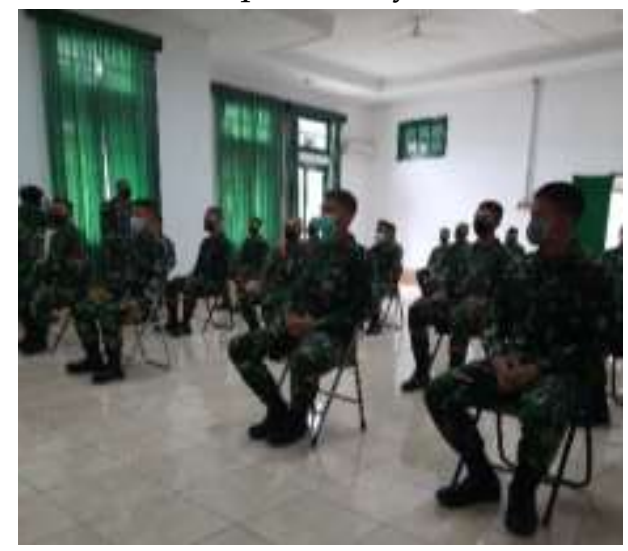

Gambar 4. Saat acara penutupan pelatihan Sumber foto: Foto pribadi (diambl pada tanggal 4 Mei 2021 di PUSDIK PENGMILUM Cimahi)

Keberhasilan. Dari peserta yang berjumlah 12 orang delapan orang berhasil memahami dan mampu berkomunikasi dengan penutur asli, menulis karangan dengan baik, memahami bacaan, film dengan baik, dua orang belum terlalu mampu dalam menulis, membaca teks dalam berkomunikasi belum lancar perlu waktu untuk menjawab pertanyaan dan sering salah menangkap maksud dalam pembicaraan. Dua orang lagi sampai waktu berakhirnya pelatihan ini hanya mampu mengucapkan beberap kalimat membaca tidak lancar, menulis dan mendengarkan audio dan menonton film tidak bisa.

Keberhasilan delapan orang ini ditunjang oleh pendidikan sebelumnya serta pengalaman di antara mereka ada yang pernah bertugas di luar negeri atau terbiasa berkomunikasi dengan orang asing. Selain itu, mereka ini memiliki daya juang, keinginan, motivasi yang tinggi. Mereka sadar akan pentingnya menguasai bahasa Rusia untuk pekerjaan mereka. 
Ketidakberhasilan peserta menurut hemat kami karena beberpa faktor di antaranya talenta, factor budaya, dan faktor pribadi dalam hal ini ada peserta yang sudah berkeluarga pada saat itu anaknya sakit sehingga pikiran peserta ini bercabang mengakibatkan terganggunnya konsentrasi peserta ini. Faktor talenta juga mempengaruhi keberhasilan pelatihan ini, tidak semua orang berbakat dan bisa belajar bahasa. Kami cukup memaklumi situasi kedua peserta ini. Faktor budaya sangat mempengaruhi seseorang dalam mempelajari bahasa. Budaya Rusia sangat berbeda dengan budaya Indonesia, misalnya dalam hal panggilan anak kepada ayahnya, orang Rusia anak memanggil nama pada ayahnya. Hal ini membuat heran peserta pelatihan. Konsep makan dalam masyarakat Rusia berbeda dengan konsep makan orang Indonesia, contoh untuk sarapan orang Rusia hanya minum kopi atau teh dan biskut atau hanya makan buah (pisang, apel dll), sedangkan orang Indonesia sarapan pagi nasi dan lauk pauk, kopi atau teh. Makan siang orang Rusia menu lengkap sup, salat, makanan utama steik ikan atau daging atau ayam setelah itu minum juice buah, air putih, sedangkan orang Indonesia tidak sebanyak itu menunya. Hal ini berpengaruh pada saat peserta membaca teks dan mereka tidak mengerti, Hal ini dijelaskan oleh pengajar sehingga mereka mempunya gambaran dan paham bagimana konsep makan orang Rusia. Selain itu, ditayangkan juga video tentang restoran, makan di keluarga Rusia.

\section{KESIMPULAN DAN SARAN}

\section{Kesimpulan}

Helikopter seri MI ini sangat diperlukan oleh TNI AD untuk tugas-tugas di daerah khususnya di Indonesia Timur. Indonesia Timur merupakan daerah yang sulit dijangkau oleh transportasi biasa karena daerah ini dikelilingi gunung-gunung.

Demi kelancaran kinerja para crew helikopter ini maka mereka perlu dilatih bahasa Rusia untuk memudahkan komunikasi mereka dengan orang Rusia.

Dalam pelatihan yang dilakukan selama tiga bulan diberikan seluruh materi gramatika semua kasus, bacaan-bacaan yang mengandung berbagai tema dan kosa kata yang beragam, percakapan berbagai tema, juga mengarang dalam tema-tema yang bervariasi. Pelatihan ini dilakukan secara intensif setiap hari.

Hasil dari kegiatan ini adalah delapan orang berhasil dengan baik berkomunikasi orang Rusia, dua orang tidak begitu berhasil dan dua orang yang tidak berhasil.

\section{DAFTAR REFERENSI}

Chudinova, V. V. (2021). Грамматика русского языка $b$ таблицах. Grammatika russkogo yazyka $v$ tablitsax. Flinta.

Funk, H. (2012). Four models of language learning and acquisition and their methodological implications for textbook design. Electronic Journal of Foreign Language Teaching. Centre for Language Studies National University of Singapore, 9(SUPPL.1), 298-311. https://e-flt.nus.edu.sg/wpcontent/uploads/2020/09/v9s12012/ funk.pdf

Glazunova, O. . (2017). Grammatika Russkogo Yazyka $v$ uprazheniyax I kommentaryax. Zlotus.

Kryuchkova Lyudmila Сергеевна Крючкова Людмила, С. (2021). Падежная и предложно-падежная система русского языка. Функционально-семантический аспект (Padezhkaya I predlozhno-padezhnaya Sistema russkogo yazyka. Funktsional'nosemanticheskiy aspek). Flinta.

Kurmaeva N. M., (Et.al). (2021). Русские глаголы. Формы и контекстное употребление. Учебное пособие (Russkie glagoly. Formy i kontekstnoe upotreblenie. Uchebnoe posobie. Flinta.

Rogacheva E.N and Cemenova L.I. (2021). Читаем русскую литературу - изучаем язык Chitaem Russkuyu luteraturu Izuchaem yazyk. Flinta.

Sundari, H.-. (2017). MODEL-MODEL PEMBELAJARAN DAN PEMEFOLEHAN BAHASA KEDUA/ASING. Pujangga, 1(2). https://doi.org/10.47313/pujangga.v 
$1 \mathrm{i} 2.321$

\section{Sumber elektronik}

(авиару.pф/aviamuseum/aviatsiya/sssr/ vertolety/vertolety-kbmilya/mnogotselevoj-vertolet-mi-172/mnogotselevoj-vertolet-mi-17-1v/) Diunduh 24-9-2021

Wawancara dengan duta besar Indonesia untuk Federasi Rusia dilakukan pada tanggal 17 September 2021 melalui zoom) Wawancara dengan pilot helicopter $\mathrm{Mi}$ Mayor Gilang dilakukan pada tanggal 7, 15 dan 20 April 2021 di Cimahi. 